\title{
Gaseous Aliphatic Aldehydes in Smoke from Burning Raw Materials of Chinese Joss Sticks
}

\author{
R. S. Lee, J. M. Lin \\ Division of Environmental Health, College of Public Health, National Taiwan \\ University, Room 1451, No. 1, Jen-Ai Road, 1st Section, \\ Taipei, Taiwan, Republic of China
}

Received: 24 November 1995/Accepted: 18 March 1996

Burning Chinese joss sticks for worship rituals is a Chinese daily routine. However, it is suspected to be a factor in the development of certain diseases. Contact dermatitis due to musk ambrette exposure in incense has been reported by Hayakwa(Hayakwa et al, 1987 a; Hayakwa et al, 1987 b). Epidemiological studies have correlated contact dermatitis with a high risk of childhood leukemia (Lowergard et al, 1987), childhood brain tumor (Preston-Martin et al, 1982), and nasopharyngeal cancer (Chen et al, 1987; Yu et al, 1990). Correlation studies of lung cancer and incense smoke have been inconclusives (MacLennan et al, 1977; Chen et al, 1990). Ames identified the mutagenic effect of the smoke from burning Chinese incense (Rasmussen, 1987). The smoke had been proved to contain polycyclic aromatic hydrocarbons (PAHs), aromatic aldehydes and aliphatic aldehydes (Schoenotol and Gibbard, 1967; Lin and Wang, 1994). This study was carried out in order to look into the aliphatic aldehydes content in smoke released from burning the various raw materials of which a Chinese joss stick is composed,

\section{MATERIALS AND METHODS}

A local manufacturer provided a kind of Chinese joss stick with dye coated on. The joss stick is composed of incense powder and a bamboo stick. The powder is a mixture of 15 different varieties of dried and ground vegetation. Table 1 shows their names and percentages in the composition. The local manufacturer also offered the fifteen raw materials. Each was ground by a grinder (Braun 2k 100, Multiquicks System 100, Germany), and sifted by a sieve with 60/60 mesh. Then powder was pressed into a mold with $3.5 \mathrm{~cm}$ height and $1.3 \mathrm{~cm}$ diameter forming a cone. The cone of material was put into a stainless steel planchette with fringe, weighted and placed in a burning chamber. The burning chamber $(68 \mathrm{X} 48 \mathrm{X} 44$ $\mathrm{cm}^{3}$ ) was constructed by using polypropylene. The chamber was purged for about 50 minutes with purified air at a flow rate of $30 \mathrm{~L} / \mathrm{min}$ and humidity of $50 \pm 3 \%$,

$\overline{\text { Correspondence to: }}$ J. M. Lin 
Table 1. Composition of a joss stick

\begin{tabular}{lc}
\hline Component & Weight percentage \\
\hline Mixed powder of & 21 \\
(1) Glycyrrhiza uralensis Fisch. & \\
(2) Cinnamomun cassia Bl. & \\
(3) Ocimum basilicum L. & \\
(4) Nardostachys chinensis Bastal. & \\
(5) Foeniculum vulgare Mill. & \\
(6) Rheum officinale Baill. & \\
(7) Radix Aucklandia & \\
(8) Asarum sieboldii Miq. & \\
(9) Magnolia liliflora Desr. & \\
(10) Eugenia caryophyllata Thumb. & \\
\hline Plain powder & 1 \\
(11) Juniperus chinensis L. var. & 2 \\
Kaizuca Hort. & 32 \\
(12) Lysimachia foenum-graecum & 10 \\
(13) Liquidambar formosana Hance. & \\
(14) Santalum album L. & 33 \\
(15) Machilus nanmu Hemsl. & \\
\hline Stem & \\
(16) Bamboo stick & \\
\hline
\end{tabular}

regulated by a Flow Temperature-Humidity Control System (Model HCS 301, Miller Nelson Research). Then the inlet and outlet of the chamber were closed and the cone of material was ignited by a nickel-chrome wire controlled by a voltage regulator. It took about $12 \pm 3$ minutes to burn each cone. Sampling began right after the end of burning, by using a 2,4-dinitrophenyl-hydrazine coated Sep-Pak DNPH silica cartridge (Part No.37500, Millipore) in $2 \mathrm{~L} / \mathrm{min}$ for $1 \mathrm{~min}$. The SepPak was eluted by $5 \mathrm{~mL}$ acetonitrile (BDH, Hipersalv, England). The high performance liquid chromatograph (HPLC, Model 590, Waters, USA) equipped with the U.V. detector set at $\lambda \max 254 \mathrm{~nm}$ was utilized to determine the derivatives. A series of standard solution of aldehyde 2,4-dinitrophenylhydrazones was prepared from a stock solution formed by spiking a mixed aldehydes standard solution (aldehydes standard solution kit, TK-151, Alltech) onto the Sep-Pak and eluting the Sep-Pak with $5 \mathrm{~mL}$ acetonitrile. A quantified 4fluorobenzonitrile (46680, Fluka) in acetonitrile $(0.134 \mathrm{~g} / 10 \mathrm{~mL})$ served as an internal standard. An aliquot $15 \mu \mathrm{L}$ sample was injected into the HPLC with a column of Nova-Pak $\mathrm{C}_{18}(150 \mathrm{~mm} \mathrm{X} 3.9 \mathrm{~mm})$ and a $0.1 \mathrm{~mL} / \mathrm{min}$ flow rate of solvent (acetonitrile/ $\mathrm{H}_{2} \mathrm{O} ; 60 / 40 \mathrm{~V} / \mathrm{V}$ ). The peak area ratio and retention time for each derivative of aldehyde relative to the internal standard was calculated when each sample was quantified. The burning weight for each raw material was obtained by substracting the residue weight from the initial weight. The yield rate 
of each aldehyde from burning each raw material was expressed in mg per gram of burning weight. The smoke generated from burning a joss stick was also analyzed for comparison. The effects of ventilation and burning rate $(\mathrm{g} / \mathrm{min})$ on the yields of aliphatic aldehydes were also demonstrated in the laboratory

\section{RESULTS AND DISCUSSION}

Table 2 shows the yields of aliphatic aldehydes when burning the component materials of a joss stick. Formaldehyde, acetaldehyde, acrolein, propanal and butanal existed in the smoke. The smoke from burning a joss stick with a bamboostick, contained a higher amount of aliphatic aldehydes than that from an incense powder mixture without bamboo. This demonstrates that bamboo is a major source of aliphatic aldehydes, especially formaldehyde, released during burning.

Table 2. Generation of aliphatic aldehydes from burning a joss stick, mixed incense powder, and a bamboo stick

\begin{tabular}{|c|c|c|c|c|}
\hline \multirow[b]{2}{*}{ Aldehydes } & \multicolumn{4}{|c|}{$\begin{array}{c}\text { Aldehyde yield from burning material at unventilated } \\
\text { conditions, mg aldehyde / g material burned }\end{array}$} \\
\hline & Joss stick & Mixed incense powder* & Bamboo & stick** \\
\hline Formaldehyde & 6.1 & 2.3 & & 7.5 \\
\hline Acetaldehyde & 3.1 & 2.1 & & 4.7 \\
\hline Acrolein & 2.7 & 1.5 & & 2.4 \\
\hline Propanal & 0.8 & 0.4 & & 0.7 \\
\hline Butanal & 0.5 & 0.6 & & 0.3 \\
\hline
\end{tabular}

Table 3 designates the yields of alphatic aldehydes when burning one gram of vegetative component. The smoke from burning Juniperus and Santalum abounded in formaldehyde. Table 4 estimates the percentage contribution of the various components in a joss stick to the formation of aliphatic aldehydes. The highest contributers to formaldehyde release were bamboo $51 \%$ and Santalum $42 \%$.

Table 5 gives the generation data of aliphatic aldehydes from burning raw material in ventilated conditions. The aldehydes yields obviously are reduced when the material is burned under ventilated conditions with a flow rate of $5 \mathrm{~L} / \mathrm{min}$.

Table 6 demonstrates that the yields of aliphatics aldehydes only slightly reduce when the burning rate of Juniper is changed from $0.02 \mathrm{~g} / \mathrm{min}$ to $0.05 \mathrm{~g} / \mathrm{min}$. 
Table 3. Generation of aliphatic aldehydes from burning the raw materials of a joss stick

Aldehyde yield from burning material at unventilated conditions, mg aldehyde / $\mathrm{g}$ material burned

\begin{tabular}{lcccccc} 
Raw material & Formal. * & Acetal.* & Acrolein & Propanal & Butanal & Total \\
\cline { 2 - 7 } Juniperus & 7.3 & 22 & 1.3 & 0.3 & 0.1 & 11.1 \\
Santalum & 6.4 & 2.2 & 1.0 & 0.3 & 0.8 & 10.7 \\
Machilus & 1.4 & 2.7 & 2.3 & 0.7 & 08 & 7.9 \\
Nardostachys & 0.8 & 2.2 & 1.8 & 0.7 & 1.5 & 6.9 \\
Liquidambar & 2.0 & 1.5 & 1.3 & 0.2 & 0.3 & 5.3 \\
Ocimum & 0.1 & 2.7 & 1.6 & 0.6 & 17 & 6.8 \\
Glycyrrhiza & 0.2 & 2.4 & 1.8 & 0.5 & 1.3 & 6.2 \\
Asarum & 0.8 & 1.7 & 1.3 & 0.6 & 1.0 & 5.4 \\
Magnalia & 08 & 2.0 & 1.3 & 0.3 & 0.5 & 4.9 \\
Lysimachia & 0.8 & 1.8 & 1.3 & 0.8 & 02 & 4.9 \\
Foeniculum & 0.1 & 2.1 & 1.3 & 0.5 & 13 & 5.3 \\
Rheum & 0.4 & 1.1 & 1.8 & 0.2 & 0.4 & 4.0 \\
Cinnamomun & 0.3 & 1.2 & 1.3 & 0.3 & 0.7 & 3.8 \\
Eugenia & 0.2 & 0.9 & 1.2 & 0.3 & 0.5 & 3.0 \\
\hline
\end{tabular}

* Formal. : Formaldehyde ; Acetal. :Acetaldehyde

Table 4. Expected contribution to the formation of aliphatic aldehydes by components of a joss stick

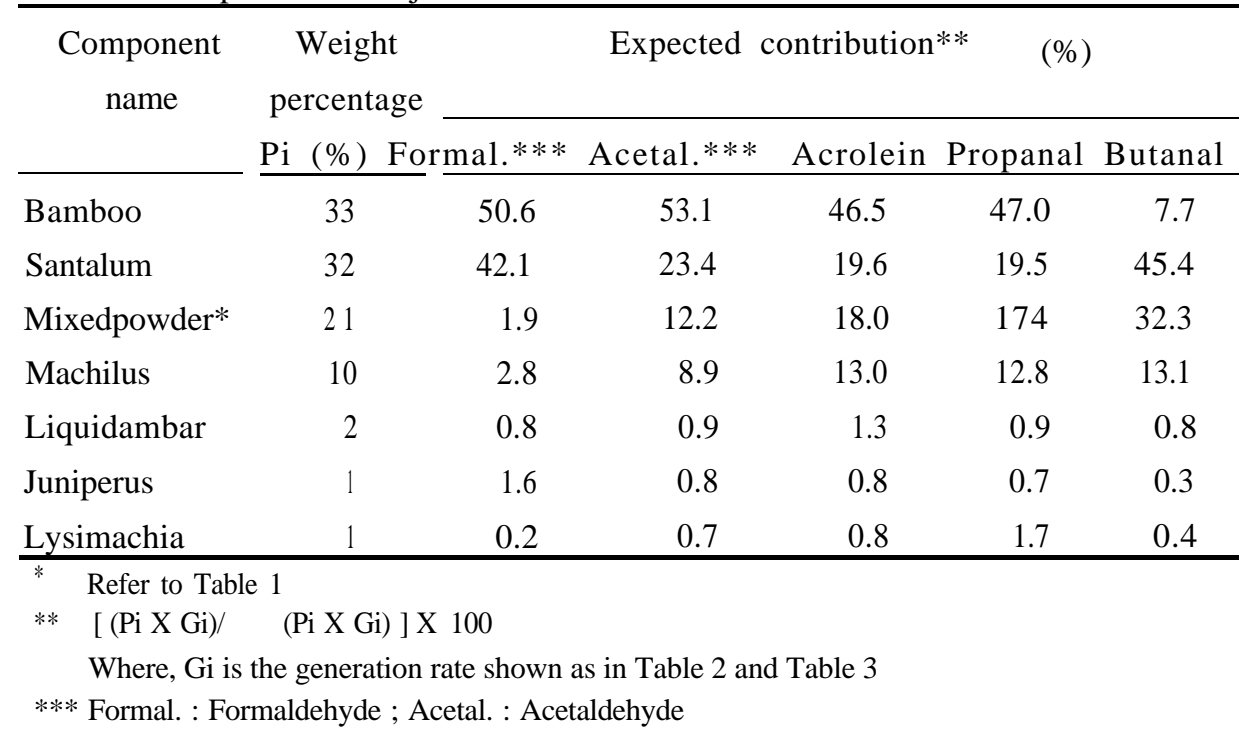


Table 5. Generation of aliphatic aldehydes from burning material under ventilated conditions and unventilated conditions

\begin{tabular}{|c|c|c|c|c|c|c|}
\hline \multirow[t]{2}{*}{$\begin{array}{l}\text { Condition with } \\
\text { material }\end{array}$} & \multicolumn{6}{|c|}{$\begin{array}{l}\text { Aldehyde yield from burning material at controlled } \\
\text { conditions, mg aldehyde / g material burned }\end{array}$} \\
\hline & Formal.* & Acetal.* & Acrolein & Propanal & Butanal & Total \\
\hline \multicolumn{7}{|l|}{ Without ventilation } \\
\hline Joss stick & 6.1 & 3.1 & 2.7 & 0.8 & 05 & 13.1 \\
\hline Bamboo & 7.5 & 4.7 & 2.4 & 0.7 & 0.3 & 15.6 \\
\hline Machilus & 1.4 & 2.7 & 2.3 & 0.7 & 0.8 & 7.9 \\
\hline Santalum & 6.4 & 2.2 & 1.0 & 0.3 & 08 & 10.7 \\
\hline Foeniculum & 0.1 & 2.1 & 1.3 & 0.5 & 1.3 & 5.3 \\
\hline Cinnamomun & 0.3 & 1.2 & 1.3 & 0.3 & 0.7 & 3.8 \\
\hline \multicolumn{7}{|l|}{$\begin{array}{l}\text { With ventilation } \\
\text { (Flow rate } 5 \mathrm{~L} / \mathrm{min} \text { ) }\end{array}$} \\
\hline Joss stick & 1.8 & 1.2 & 1.3 & 0.4 & 0.8 & 5.4 \\
\hline Bamboo & 4.6 & 3.4 & 2.0 & 0.5 & 01 & 10.6 \\
\hline Machilus & 0.6 & 1.2 & 1.1 & 0.1 & 0.1 & 3.2 \\
\hline Santalum & 1.8 & 1.1 & 0.7 & 0.2 & 0.4 & 4.1 \\
\hline Foeniculum & 0.1 & 2.5 & 1.2 & 0.3 & 01 & 4.2 \\
\hline Cinnamomun & 0.3 & 0.8 & 07 & 0.2 & 0.1 & 2.1 \\
\hline
\end{tabular}

* Formal. : Formaldehyde ; Acetal. : Acetaldehyde

Table 6. Relationship between aliphatic aldehyde yields and the burning rate of Juniperus

\begin{tabular}{ccccccc}
\hline Burning rate & \multicolumn{5}{c}{$\begin{array}{c}\text { Aldehyde yield from burning material at unventilated conditions, } \\
\text { mg aldehyde / } \mathrm{g} \text { material burned }\end{array}$} \\
\cline { 2 - 7 }$(\mathrm{g} / \mathrm{min})$ & Formal.** $^{* *}$ & Acetal.** & Acrolein & Propanal & Butanal & Total \\
\hline 0.02 & 7.5 & 2.3 & 1.7 & 0.4 & 0.3 & 12.3 \\
0.04 & 6.9 & 24 & 12 & 0.4 & 0.1 & 10.9 \\
0.05 & 7.4 & 1.9 & 0.9 & 0.2 & ND* & 10.4 \\
\hline
\end{tabular}

* ND, non-detectable

** Formal. : Formaldehyde ; Acetal. : Acetaldehyde 


\section{REFERENCES}

Chen CJ, Wang YF, Shieh T, Chen JY, and Liu MY (1987) Multifactorial etiology of nasopharyngeal carcinoma. Head and Neck Oncology Research Conference 10-12:469-476

Chen CJ, Wu HS, Chuang YC, Chang AS, Luh KT, Chao HH, Chen KY, Chen SG, Lai GM, Huang HH, and Lee HH (1990) Epidemiologic characteristics and multiple risk factors of lung cancer in Taiwan. Anticancer Res 10:971-976

Hayakawa R, Matsunaga K, and Arima Y (1987 a) Depigmented contact dermatitis. Contact Dermatitis 16:272-274

Hayakawa R, Matsunaga K, and Arima Y (1987 b) Airborne pigmented contact dermatitis due to musk ambrette in incense. Contact Dermatitis 16:96-98

Lin JM, and Wang LH (1994) Gaseous aliphatic aldehydes in Chinese incense smoke. Bull Environ Contam Toxicol 53:374-381

Lowergard RA, Peters JM, Cicioni C, Buckley J, Brenstein L, Preston-Martin S, and Rappaport E (1987) Childhood leukemia and parents occupational and home exposures. J Natl Cancer Intst 79(1):39-46

MacLennan R, Costa JD, Day NE, Law CH, Ng YK, and Shanmugaratnam K (1977) Risk factors for lung cancer in Singapore Chinese, A population with high female incidence rates. Int J Cancer 20:854-860

Preston-Martin S., Yu MC, Benton B, Henderson BE (1982) N-nitroso compounds and childhood brain tumors: A case-control study. Can Res 42:5240-5245

Rasmussen RE (1987) Mutagenic activity of incense smoke in Salmonella typhimurium. Bull Environ Contam Toxicol 38:827-833

Schoenotol R, and Gibbard S (1967) Carcinogens in Chinese incense smoke (letter) Nature 216:612

Yu MC, Garabrant DH, Huang TB, Henderson BE (1990) Occupational and other nondietary risk factors for nasopharyngeal carcinoma in Guanzhou China Int $\mathrm{J}$ Cancer 45:1033-1039 